\title{
UMA HIPÓTESE SOBRE A POSSÍVEL ORIGEM DA AÇÃO DECENDIÁRIA OU AÇÃO DE ASSINAÇÃO DE DEZ DIAS NAS ORDENAÇÕES MANUELINAS
}

\author{
A HYPOTHESIS ABOUT A POSSIBLE ORIGIN OF THE “AÇÃO DECENDIÁRIA” OR “AÇÃO DE \\ ASSINAÇÃO DE DEZ DIAS” IN THE MANUELINAS ORDINANCES
}

Fernando Mil Homens Moreira ${ }^{*}$

\begin{abstract}
Resumo:
Aqueles que escreveram sobre a "ação decendiária" ou "ação de assinação de dez dias", que surgiu no direito português nas Ordenações Manuelinas, afirmam de forma peremptória - e sem quaisquer questionamentos ou mesmo maior reflexão -, que tal instituto é criação genuinamente lusitana - do que se discorda (e as razões desta discordância serão expostas neste trabalho). O objetivo deste estudo é, portanto, apenas levantar uma nova hipótese sobre uma possível origem da "ação decendiária" ou "ação de assinação de dez dias" e, com isso, tentar alargar a visão sobre a História deste instituto.

Palavras-chave: História do Direito português. "Ação decendiária". "Ação de assinação de dez dias". Ordenações Manuelinas. Origem. Nova hipótese.
\end{abstract}

\begin{abstract}
:
Those who wrote about the "ação decendiária" or "ação de assinação de dez dias" (10-day for payment injunction), that appeared in the Portuguese law at the Manuelinas Ordinances, ("Ordenações Manuelinas"), assert peremptorily - and without any questionings or critical thought -, that such injunction is a genuine Lusitanian creation - with which this article's author disagrees (and the reasons of such dissension will be demonstrated in this paper). Therefore, the aim of this paper is to only raise a new hypothesis about a possible origin of the "ação decendiária" or "ação de assinação de dez dias" and with this try to broaden the vision of the History of such judicial proceeding.
\end{abstract}

Keywords: History of Portuguese law. "Ação decendiária". "Ação de assinação de dez dias". Manuelinas Ordinances. Origin. New hypothesis.

1. Breve introdução: o limitado objetivo deste estudo

O objetivo deste estudo é apenas levantar uma hipótese sobre uma possível origem do instituto da "ação decendiária" ou "de assinação de dez dias", que surgiu no direito lusitano nas Ordenações Manuelinas. Não se tem, portanto, qualquer pretensão de

\footnotetext{
Bacharel em Direito pela Faculdade de Direito da Universidade de São Paulo, especialista em Direito Processual Civil pela Faculdade de Direito da Università degli Studi di Milano (Statale), Milão, e doutorando e Direito Processual Civil na Faculdade de Direito da Universidade de São Paulo. Assessor de Ministro do Supremo Tribunal Federal.
} 
tentar comprovar a hipótese aqui levantada, eis que se acredita que tal tarefa demandaria muitos anos de pesquisa.

A justificativa na escolha do tema a ser estudado reside no fato de não se ter notícia da existência de qualquer estudo, seja em Portugal e muito menos no Brasil, que aborde a questão, tal como aqui proposta. Com efeito, em quase tudo que se leu a respeito da "ação decendiária" há afirmação peremptória - e sem quaisquer questionamentos ou mesmo maior reflexão - de que tal instituto é criação genuinamente lusitana ${ }^{1}$ - do que se discorda (e as razões desta discordância serão expostas neste trabalho).

De fato, sem querer, de forma alguma, desmerecer o trabalho dos juristas manuelinos (Ruy Boto, Ruy da Grã, João Cotrim, João de Faria, Pedro Jorge e Cristovão Esteves $)^{2}$ - muito pelo contrário, eis que deve ser exaltado, porquanto a introdução em Portugal, nas Ordenações Manuelinas, de um procedimento do tipo monitório representou um enorme avanço no direito lusitano -, e, a exemplo do que diz Eduardo Talamini, não se duvide que a "ação decendiária", tal como estruturada com seus detalhes procedimentais, talvez não encontre exato equivalente nos outros sistemas; é inegável, todavia, que a essência da ação de assinação de dez dias não é criação lusitana ${ }^{3}$ - e é essa a hipótese que se pretende aqui estudar.

Lamentavelmente, contudo, não será possível aprofundar o estudo do tema desta investigação e tentar, de alguma forma, comprovar a hipótese aqui levantada - o que, todavia, se entende não ser trabalho em vão, eis que este estudo talvez possa (pelo menos é isso que se espera) servir de ponto de partida para outros estudiosos da história do processo civil interessados no estudo da "ação decendiária". O que se quis com esse estudo, portanto, foi apenas tentar alargar a visão histórica sobre as origens da "ação decendiária".

2. Rápida análise das características essenciais da "ação decendiária" ou "de assinação de dez dias" das Ordenações Manuelinas

Como afirma José Rubens de Moraes, a crescente complexidade das relações sociais e econômicas decorrentes da epopéia das navegações no final do século XV e início do século XVI impactou o campo jurídico português, "tornando-se explícita

\footnotetext{
1 A exemplo do que dizem Pereira e Souza (SOUZA, Joaquim José Caetano Pereira e. Primeiras linhas sobre o processo civil. Accommodadas ao foro do brasil ate o anno de 1877 por augusto teixeira de freitas. Rio de Janeiro: H. Garnier, 1907. p. 405, nota 900) e Almeida Oliveira (OLIVEIRA, Antônio de Almeida. A assignação de dez dias no foro commercial e civil. Nova ed. corr. Lisboa: A. M. Teixeira, 1915. p. 16).

2 Cf. AZEVEDO, Luiz Carlos de. O reinado de D. Manuel e as Ordenações Manuelinas. Revista da Faculdade de Direito, São Paulo, v. 95, p. 19-32, jan./dez. 2000. p. 23.

3 TALAMINI, Eduardo. Tutela monitória: a ação monitória - Lei 9.079/95: doutrina, jurisprudência anotada, aproximadamente 200 acórdãos. 2. ed. rev., atual. e ampl. São Paulo: Revista dos Tribunais, 2001. p. 35.
} 
a inadequação do vetusto ordenamento Afonsino de raízes centenárias, remontando ao tempo da fundação da monarquia lusitana, às novas expectativas e necessidades dos novos tempos". De fato, “o novo panorama demandava que inúmeras mudanças fossem conduzidas no campo das leis, no sentido de corrigir desvios, propiciar adequações, enfim, dar correta interpretação aos muitos textos legais dispersos, adequando-os a esta nova realidade social e, principalmente, econômica". ${ }^{4}$

Com efeito, segundo Luiz Carlos de Azevedo,

até o período em que $\mathrm{D}$. Manuel assumiu o trono, a legislação extravagante engrossara, exigindo a necessidade de se promulgar novo édito, que àquele primeiro substituísse. Por outro lado, era preciso atualizar e dar correta interpretação aos textos legais, ainda vinculados a um passado que a renovação das idéias exigia. ${ }^{5}$

Dessa forma, em 1514 ficou pronta uma primeira impressão das Ordenações Manuelinas, substituída por outra, definitiva, em 1521, já às vésperas da morte de D. Manuel I. ${ }^{6}$ No Livro 3, das novas Ordenações, vem previsto, no título 16, cujo nome é: "Em que maneira se procederá contra os demandados por escrituras públicas, ou alvarás que têm força de escritura pública, ou reconhecidas pela parte", ${ }^{7}$ um novo tipo de procedimento que a doutrina praxista outorgou o nome de "ação decendiária" ou de "ação de assinação de dez dias", que era destinado ao credor que pretendia haver do devedor quantia ou coisa que este se obrigara, mediante prova por "escritura pública" da obrigação ou "alvará feito e assinado" pelo devedor; conforme se pode conferir no seguinte trecho do proêmio:

PORQUE as demandas, que fam fundadas em efcripturas pubricas, deuem com muita razam mais breuememe de feer acabadas, e pêra que os creedores poffam fem delonga cobrar o que lhe for deuido e feu paguamento fe nom delongue com as maliciofas excepçoẽs, que os deuedores muitas vezes poem ao que per efcripturas pubricas fam obrigados, Mandamos que, tanto que algũa peffoa em Juizo demandar outra por razam dalgũa coufa, ou quantidade, que lhe feja obriguada dar, ou entreguar, e o Autor amoftrar efcriptura pubrica da dita obriguaçam, ou Aluará feito, e affinado por tal

4 Cf. MORAES, José Rubens de. Evolução histórica da execução civil no direito lusitano. 2005. Dissertação (Mestrado) - em direito processual civil - USP. pp. 222 e 228.

5 Cf. Azevedo, Luiz Carlos de. O Reinado de D. Manuel e as Ordenações Manuelinas. Revista da Faculdade de Direito, São Paulo, v. 95, p. 19-32, 2000. cit. p. 23.

6 Id. Ibid., p. 24 e Introdução à história do direito. 2. ed., rev. e ampl. São Paulo: Revista dos Tribunais. 2007. p. 293.

7 Cf. Ordenaçoens do Senhor Rey D. Manuel. Livro III. Coimbra: Real Imprensa da Universidade. 1797. p. 65 e ss. Disponível em: <http://www.iuslusitaniae.fcsh.unl.pt/verlivro.php?id_parte=91\&id_obra=72\&pagina=86>. Acesso em: 10 dez. 2008. 
peffoa a que fe deua dar tanta fee como a efcriptura pubrica, o Juiz que de tal caufa conhecer affine loguo termo de dez dias perentorios a effe, que fe affmoftrar feer obriguado, a que pague ao Autor todo o na dita efcriptura, ou Aluará contehudo, ou amoftre pagua, ou quitaçam, ou alegue, e proue dentro dos ditos dez dias qualquer outra razam de embarguos, que teuer a nom paguar, ou comprir o que affi por a dita efcriptura, ou Aluará fe moftrar feer obriguado; e paffados os ditos dez dias nom amoftrando, nem prouando o Reo pagua, ou quitaçam, ou outra tal razão que o defobrigue de paguar, feja logo condenado por fentença, que pague ao Autor todo aquello em que affi fe moftrar feer obriguado. ${ }^{8}$ (destacado).

Essa nova ação deveria estar aparelhada em documentos sem eficácia de título executivo (escrituras, a princípio públicas ${ }^{9}$ ou documento feito e assinado pelo réu), que "por si mesmo fazem prova legal"10 da obrigação, que, a princípio, deveria ser de pagar soma em dinheiro ou entregar coisa (conforme é até mesmo expresso nas Ordenações Manuelinas em 3.16, proêmio). ${ }^{11}$

8 Cf. Ordenaçoens do Senhor Rey D. Manuel. Livro III. Coimbra: Real Imprensa da Universidade. 1797. p. 65-66. Disponível em: <http://www.iuslusitaniae.fcsh.unl.pt/verlivro.php?id_parte=91\&id_obra=72\&pagina=86>. Acesso em: 10 dez. 2008.

9 Ao tratar da ação decendiária em época bem mais moderna às Ordenações Manuelinas, (OLIVEIRA, Antônio de Almeida. A assignação de dez dias no foro commercial e civil. Nova ed. corr. Lisboa: A. M. Teixeira, 1915), afirma que essa escritura poderia ser pública ou particular, mas deveria ser obrigatoriamente: i) autêntica (op. cit. p. 43-45), eis que, por exemplo, a escritura que "um indivíduo faz por orphão de que não é tutor" não é autêntica; ii) solene (op. cit. p. 45-50), isto é, feita "com todas as soleminidades legaes, de modo que tenha authenticidade de publico ou força de publico"; razão pela qual, "a escriptura publica feita sem intervenção das testemunhas exigidas pela lei ou não subscripta pelas partes" não servia à decendiária; iii) original (op. cit. p. 50-56), vale dizer, "não exhibido em traslado, ou então constante de traslado authentico", "salvo [se o traslado] é antigo, o que se diz quando excede a 30 ou 40 anos"; e iv) incondicional (op. cit. p. 57-58), isto é, "não subjeito a prazo ou condição alguma". No mesmo sentido, Pereira e Souza, ao tratar da ação de assinação de dez dias das Ordenações Filipinas (SOUZA, Joaquim José Caetano Pereira e. Primeiras linhas sobre o processo civil. Accommodadas ao Foro do Brasil ate o anno de 1877 por Augusto Teixeira de Freitas. Rio de Janeiro: H. Garnier, 1907. p. 405, nota 901).

10 Cf. Oliveira, Antônio de Almeida. A assignação de dez dias no foro commercial e civil. Nova ed. corr. Lisboa: A. M. Teixeira, 1915. p. 17.

11 Antônio de Almeida Oliveira afirma, entretanto, que era possível igualmente ajuizar a ação decendiária para cobrança de obrigações de fazer e de deixar de fazer, desde que "contendo taes obrigações interesses apreciaveis em dinheiro" (op. cit. p. 36). A obrigação deveria ser sempre certa e líquida, porquanto "é impossivel ter acção decencial o escripto de divida, cujo quantum é ignorado, e não se prova incontinenti por documentos ou confissão da parte." (op. cit. p. 68). Contudo, poderia haver iliquidez tanto no valor do crédito, quanto à incerteza quanto à pessoa obrigada. Quanto a essa, ficava afastada ante o teor da escritura pública. Quanto àquela, era possível tanto a liquidação de forma preparatória à ação, como no ato da propositura da ação decendiária (op. cit. p. 68-69). Igualmente nesse sentido, v. Manuel de Almeida e Sousa Lobão (LOBÃO, Manuel de Almeida e Sousa. Tratado pratico compendiario de todas as acções summarias. Lisboa: Imprensa Nacional, 1867. p. 437). A obrigação igualmente deveria ser eficaz, isto é, não eivada de "vício de fundo", pois "de um contracto nullo não nasce aç̧ão alguma" (cf. OLIVEIRA, Antônio de Almeida. op. cit. p. 72) e bilateral, razão pela qual o crédito cobrado na ação decendiária não poderia estar condicionado 
Em relação ao procedimento, “iniciará o processo por via de requerimento, acompanhado do titulo da divida, no qual exponha a obrigação do reu, e peça que seja elle citado para na primeira audiencia do juiz ver se lhe assignar o decendio, em que tem de pagar a divida, ou allegar e provar a excepção ou defeza que tiver, sob pena de ser condemnado á revelia". ${ }^{12} \mathrm{O}$ prazo de dez dias era peremptório (Ordenações Manuelinas em 3.16, proêmio). ${ }^{13}$

Nas Manuelinas (3.16), se passados os ditos dez dias e o réu não demonstrasse ou provasse o pagamento, quitação, ou outro motivo que o desobrigasse de pagar, era "logo condenado por fentença" e, além de ser condenado no principal, pagava "por pena da maa caufa que defendeo outro tanto como o principal, da qual pena a metade ferá pera a Piedade, e a outra metade para o Autor" (3.16.2). Em seguida, procedia-se à execução. $\mathrm{O}$ réu igualmente era condenado ao pagamento na hipótese de revelia, procedendo-se à execução (3.16.1). Por outro lado, se o réu provasse que não devia a obrigação demandada pelo autor, este era desde logo condenado a pagar ao réu o principal e "mais outro tanto de pena" (ou seja, o dobro do principal), à "piedade" (3.16.1).

A "ação decendiária" das Ordenações Manuelinas tinha, portanto, procedimento sumário com as seguintes características essenciais: (i) contraditório postergado, pois o juiz ouvia apenas o autor para a expedição do mandado monitório ao réu, que só após recebê-lo poderia se opor ao mandado; (ii) o juiz expedia ordem ao réu para que, no prazo de 10 (dez) dias, pagasse ou provasse não dever, e que (iii) tinha por objetivo propiciar, de forma mais abreviada, a execução de obrigações representadas por documentos escritos sem força executiva. Como se nota, a "ação decendiária" ou de "assinação de dez dias", introduzida nas Ordenações Manuelinas (3.16), tem procedimento muito semelhante, pelo menos em essência, à "ação monitória", ${ }^{14}$ prevista no CPC atual (art. 1.102 “a", "b" e "c").

Analisar-se-á em seguida um instituto do tipo monitório, que já existia no direito estatutário italiano muito antes do surgimento da "ação decendiária" nas Ordenações Manuelinas; porquanto, como diz José Rogério Cruz e Tucci, "Tendo sido muito fecunda a influência do ius commune nas fontes jurídicas da Península Ibérica, é de

ao cumprimento de uma cláusula a que o credor, autor da ação, tenha se obrigado (cf. LOBÃO, Manuel de Almeida e Sousa. op. cit. p. 442). Além disso, a obrigação representada pela escritura pública deveria ser assumida entre as mesmas partes presentes na relação processual. Excluía-se, portanto, o cabimento da decendiária se tivesse que ser promovida contra herdeiro do devedor. A limitação na legitimidade de partes, aliás, se fazia presente tanto no pólo ativo como no passivo (cf. LOBÃO, Manuel de Almeida e Sousa. op. cit. p. 429-430).

12 Cf. OLIVEIRA, Antônio de Almeida. A assignação de dez dias no foro commercial e civil. Nova ed. corr. Lisboa: A. M. Teixeira, 1915. p. 183.

13 Id. Ibid., p. 184.

14 Cf. AZEVEDO, Luiz Carlos de. Introdução à história do direito. 2. ed., rev. e ampl. São Paulo: Revista dos Tribunais, 2007. p. 194. 
supor-se que aquela técnica vigente no âmbito do direito romano-canônico tenha inspirado os legisladores do reino lusitano". ${ }^{15}$

3. O praeceptum executivum sine causae cognitione ou mandatum de solvendo cum clausula iustificativa

Embora um processo com alguma fisionomia de processo monitório fosse desconhecido tanto para o direito romano, como para os glosadores e canonistas até o Século XIII, ${ }^{16}$ traços embrionários mais remotos desse instituto podem ser identificados já na legislação estatutária italiana ${ }^{17}$ do Século X, que admitia duas espécies de procedimento, uma ordinária, que era a regra, e outra mais breve que constituía a exceção: os estatutos dividiam as controvérsias cíveis em ordinárias e sumárias, prevendo para estas uma solução mais rápida.

No Século XII, enquanto as influências do domínio bárbaro iam caindo gradualmente, ${ }^{18} \mathrm{o}$ direito romano ia ressurgindo através dos estudos dos glosadores com a interpretação do Corpus Juris Civilis. Paralelamente, o direito canônico alastrava-se por toda a cristandade, surgindo assim, o Direito Romano-Canônico.

Depois da elaboração do Solemnis Ordo Iudiciarius romano-canônico, surgiu a necessidade de se corrigir a interminável duração dos processos. No entanto, Pietro Sella ${ }^{19}$ e Tommaso Siciliani ${ }^{20}$ afirmam que não se notou qualquer indicação de um verdadeiro e próprio procedimento célere antes do Século XIII: neste século tem-se menção a um procedimento rápido, tanto nos estatutos italianos como nos tratados, ao qual freqüentemente as cidades italianas recorriam a fim de assegurar aos seus próprios cidadãos a tutela jurídica, mesmo fora das fronteiras da cidade. Por exemplo, em 1288, a convenção entre Gênova, na Itália, e Grasse, na França, que reproduzindo os termos do acordo precedente de 1198, introduziu a possibilidade de proceder-se summarie et de plano nas controvérsias recíprocas.

No final do Século XIII o procedimento estatutário italiano começou a transformar-se e, assim, as normas processuais iam se tornando relativamente muito

15 TUCCI, José Rogério Cruz e. Ação monitória: Lei 9.079, de 14.7.1995. 3. ed. rev. atual. e ampl. São Paulo: Revista dos Tribunais, 2001. p. 37.

16 Cf. SICILIANI, Tommaso. Procedimento per ingiunzione. In: Nuovo digesto italiano. Torino: UTET, 1938. v. 16, p. 1.096.

17 Cf. SELLA, Pietro. Il procedimento civile nella legislazione statutaria italiana, Milano: Hoepli, 1927. p. 216.

18 Cf. CALASSO, Francesco. Medio evo del Diritto. Milano: Giuffrè, 1954. v. 1, p. 345-353.

19 SELLA, Pietro. Il procedimento civile nella legislazione statutaria italiana. Milano: Hoepli, 1927. p. 218.

20 SICILIANI, Tommaso. Procedimento per ingiunzione. In: Nuovo digesto italiano. Torino: UTET, 1938. v. 16, p. 1.096. 
mais precisas e quase todos os estatutos usaram uma fórmula característica para designar os procedimentos rápidos: summatim, sine strepitu iudicii, sine figura iudicii, de plano, prevale summarie, summaria cognitio.

Assim, sob esse influxo renovatório, do incremento das relações mercantis - e por força, principalmente, das obras dos glosadores Baldo de Ubaldis e Lanfranco -, surgiu no inicio do Século XIV na Itália, com figuras similares na Alemanha, Áustria e Suíça, um processo que se pode dizer que tenha dado origem ao processo monitório, qual seja, o "praeceptum executivum sine causae cognitione" ou "mandatum de solvendo cum clausula iustificativa", condicionado, na sua executividade, pelo "nisi se opponat". Esse processo foi inspirado no procedimento canônico da summaria cognitio, que tinha por objetivo a abreviação da duração dos processos. ${ }^{21}$

Por meio desse procedimento ficava o juiz autorizado a emitir em favor do credor - e sem a prévia citação do devedor - ordem de pagamento envolvendo pequenos créditos (o mandatum de solvendo), que permitia a execução; mas essa ordem devia vir acompanhada da clausula iustificativa, ou seja, a de que o devedor, querendo opor defesa, deveria fazê-lo dentro de um certo tempo. Nesse sentido, esclarece Chiovenda ${ }^{22}$ que:

[...] para determinados créditos, posto que não constantes de documentos, estabeleceu-se no direito medieval italiano o uso de não citar em juízo o devedor, mas de obter diretamente do juiz a ordem de prestação que ensejava a execução, isto é, o mandatum ou praeceptum de solvendo. Não obstante, esse mandatum de solvendo era acompanhado e justificado pela cláusula de que, se o devedor se propusesse a alegar exceções, podia opô-las dentro de certo prazo, cláusula que se qualificou de clausula iustificativa e que assim rezava: 'Si senserit se gravatum' ou 'nisi se opponat'; ou em italiano: 'Salvo l'ingiunto abbia cause in contrario'.

Notificado o mandatum ao devedor, se ele não apresentasse oposição no prazo, o mandatum executava-se de pronto. Se, ao contrário, o devedor se opusesse, a oposição tolhia qualquer efeito ao mandatum, que se resolvia in vim simplicis citationis, quer dizer: dava lugar a um processo pelo rito ordinário. A cognição na primeira fase era incompleta, visto que, no momento em que expedia a ordem, o juiz ignorava se o devedor tinha exceções a opor, e só conhecia de modo superficial os fatos constitutivos da ação (pelo que se dá também ao mandato a denominação de "praeceptum executivum sine causae cognitione"). ${ }^{23}$

${ }^{21}$ Cf. SICILIANI, Tommaso. Procedimento per ingiunzione. In: Nuovo digesto italiano. Torino: UTET, 1938. v. 16, p. 1.096 .

22 CHIOVENDA, Giuseppe. Istituzioni di diritto processuale civile. Napoli: Jovene, 1950. v. 1, p. 226.

23 Cf. CHIOVENDA, Giuseppe. Istituzioni di diritto processuale civile. Napoli: Jovene, 1950. v. 1, p. 227. 
Como se nota, o procedimento do "praeceptum executivum sine causae cognitione" ou "mandatum de solvendo cum clausula iustificativa" tem muitas semelhanças com o procedimento monitório, razão pela qual se pode dizer que ele foi o embrião dos procedimentos monitórios posteriores.

De fato, as semelhanças procedimentais entre a "ação decendiária" ou a "ação de assinação de dez dias" das Ordenações Manuelinas e o "mandatum de solvendo cum clausula iustificativa" são evidentes (em ambos se nota o contraditório postergado, a expedição de ordem para pagamento ou justificativa, dentro de certo prazo e a possibilidade de oposição de defesa que tolhia a executividade da ordem monitória). O "toque genuíno" do instituto das Ordenações Manuelinas está no fato de ter positivado e ampliado o rol de documentos que poderiam dar suporte ao procedimento monitório.

Tais semelhanças procedimentais entre o instituto monitório do direito estatutário italiano e aquele das Ordenações Manuelinas não parecerem ter sido fruto de mera coincidência. De fato, como dito na introdução deste trabalho, se tem sérias dúvidas sobre a genuinidade lusitana da essência da "ação decendiária", tendo em vista a profunda influência italiana em Portugal nos séculos XV e XVI, sobre a qual se tratará a seguir.

4. O contexto sócio-econômico no qual surgiu a "ação decendiária" ou "ação de assinação de dez dias": as intensas relações entre Portugal e Itália

A hipótese levantada neste estudo, sobre uma possível origem da "ação decendiária", tem como motivação a forte ligação histórica entre Portugal e diversas cidades-estado italianas, nomeadamente Gênova e Florença, e a demonstração do quanto essa ligação foi importante para a formação do ambiente social, econômico, cultural e científico em Portugal durante a fase áurea dos descobrimentos ultramarinos lusitanos.

As viagens de descobrimento e colonização foram os mais importantes acontecimentos em Portugal, nos séculos XV e XVI, condicionando, em maior ou menor grau, grande parte dos aspectos culturais, econômicos e sociais lá existentes. A expansão marítima constituiu, de diversas maneiras, e especialmente no século XVI, a dimensão moderna de Portugal no período, ocasionando a formação de um novo quadro da configuração do mundo, o crescimento do grande comércio e das cidades e o desenvolvimento de um olhar empírico em certas áreas do saber, ${ }^{24}$ com intenção renovação do conhecimento e das $\operatorname{artes}^{25}$ e a participação italiana, para tanto, foi muito grande.

24 Cf. BELLINI, Lígia. Notas sobre cultura, política e sociedade no mundo português do século XVI. Tempo, Rio de Janeiro, v. 4, n. 7, p. 143-167, 1999. cit. p. 146.

25 Cf. AZEVEDO, Luiz Carlos de. O Reinado de D. Manuel e as Ordenações Manuelinas. Revista da Faculdade de Direito, São Paulo, v. 95, p. 19-32, jan./dez. 2000. cit. p. 21. 
Com a queda de Constantinopla em 1453, comerciantes de algumas cidadesestado italianas, especialmente Florença e Gênova, optaram por investir em Portugal. De fato, embora a rota de comércio pelo mar Vermelho e mar Mediterrâneo tivesse permanecido aberta, havia circulação restrita. ${ }^{26}$ Foi nesse quadro que o litoral português assumiu importância no final do século XV para os italianos. ${ }^{27}$ Como fica aproximadamente na metade do percurso entre a Itália e o mar do Norte, Portugal passou a constituir um excelente ponto de escala e de abastecimento para os mercadores italianos.

Com efeito, nos séculos XV e XVI, a região onde é hoje a Itália $^{28}$ era a economicamente mais avançada da Europa, ${ }^{29}$ ao passo que Portugal e Castela eram economicamente mais atrasados; razão pela qual a contribuição italiana para os descobrimentos portugueses foi muito grande. ${ }^{30}$

Todavia, o início da colaboração entre italianos e portugueses é tradicionalmente datado de 1317, quando D. Dinis, na tentativa de modernizar e organizar a frota real, firmou um acordo com o genovês Manuel Pessagno ("Pessanha" para os lusos), conferindo-lhe o título de almirante-mor e obrigando-o não só a colocar à disposição da Coroa lusitana a sua experiência náutica e comercial mas, também, que ele e seus descendentes assegurassem a presença constante em Portugal de outros vinte genoveses "sabedores do mar". Trata-se, com efeito, de um acordo bilateral, cujos vínculos jurídicos repercutiram no desenvolvimento da marinha portuguesa e na sua utilização comercial e política. Todavia, mesmo antes dessa data histórica, apesar de não estar perfeitamente documentada historicamente, parece confirmada a presença de italianos da Ligúria e de Pisa em Portugal durante o século XII. ${ }^{31}$

Como conseqüência direta da intensificação das viagens marítimas entre o Mediterrâneo e o Atlântico, os contatos entre italianos e portugueses tornaram-se

26 Cf. PESTANA, Fabio Ramos. No tempo das especiarias. São Paulo: Contexto, 2007. p. 41.

27 Cf. RADULET, Carmen. Os descobrimentos portugueses e a Itália: ensaios filológico-literários e historiográficos. Trad. de Edite Caetano. Intro. de Luis de Albuquerque. Lisboa: Vega, 1991. pp. 62/64.

28 Lembrando que em tal época, a península itálica não era uma nação, eis que dividida em muitas cidadesestado independentes, cujo desenvolvimento (a partir do século XI) deu novo impulso à vida econômica e cultural do norte e centro da Itália, caracterizado pelo Humanismo e o Renascimento, que tiveram grande influência no resto da Europa.

29 Durante o século XV, o comércio veneziano e o comércio genovês são muito prósperos, como também o são as indústrias têxteis de Milão, de Florença e de várias outras cidades italianas. (Cf. MAURO, Frédéric. Portugal, o Mediterrâneo e o Atlântico em 1493 e 1993. Tradução por Carlos A. A. Ferraz e Araújo. Politéia: História e Sociedade, Vitória da Conquista, v. 2, n. 1, p. 13-20, 2002. cit. p. 18).

30 Cf. ARNOLD, David. A Época dos descobrimentos: 1400-1600. Tradução rev. e prefaciada por Luís Felipe Barreto. Lisboa: Gradiva, 1983. p. 27-28.

31 Cf. RADULET, Carmen. Relações de Portugal com a Itália. In: Albuquerque, Luís de (Dir.). Dicionário de história dos descobrimentos portugueses Lisboa: Caminho, 1994, v. 1. p. 535; e Os italianos em Portugal. In: Chandeigne, Michel (Org.). Lisboa Ultramarina, 1415-1580: a invenção do mundo pelos navegadores portugueses. Rio de Janeiro: Jorge Zahar, 1992. p. 95. 
cada vez mais intensos e concretizaram-se através da realização progressiva de acordos de navegação e comércio. Assim, por exemplo, D. Afonso IV concede a partir de 1338 privilégios de navegação e comércio a florentinos (sobretudo à companhia comercial dos Bardi), lombardos e genoveses, enquanto D. Fernando I assina um contrato, em 1370, com Gênova para a defesa dos mercadores genoveses contra os ataques dos corsários portugueses. Por sua vez, D. João I confirma parte dos privilégios obtidos anteriormente pelos italianos e subscreve, em 1392, um acordo entre seu país e Veneza, e, em 1395, torna os genoveses e os lombardos sob sua proteção direta. Essa constante abertura dos portos portugueses à navegação italiana criou as bases de uma colaboração não só muito intensa, mas também diversificada: por um lado, sobretudo casas comerciais florentinas e genovesas e mercadores provenientes de várias regiões italianas escolheram Lisboa como sede para as próprias atividades, não só na Península Ibérica, mas também para as relações com a Inglaterra e com os Países Baixos; por outro lado, navegadores italianos, independentemente do "contrato Pessanha", ofereceram-se para navegar nas frotas portuguesas. ${ }^{32}$

$\mathrm{Na}$ fase iniciada pela viagem de Vasco da Gama em 1498 e pelo descobrimento do caminho marítimo para o Oriente, nota-se uma transformação da função e da importância dos italianos que operavam em Portugal. A presença italiana não só aumentou consideravelmente, ${ }^{33}$ mas envolveu diferentes campos de ação; além de participarem como navegadores das frotas portuguesas, os italianos organizaram expedições comerciais, e, nas várias praças do Oriente, atuaram como feitores, mercadores ou aventureiros a serviço da Coroa portuguesa. As várias casas comerciais italianas que se estabeleceram em Lisboa, não só as mais antigas - (por exemplo, os Bardi, Lomellini, Marchioni ou Sernigi), já parcialmente integradas nas estruturas econômicas, sociais e políticas locais -, mas também outras (Giraldi, Gualterotti, Cambini, Gondi, Affaitadi, Frescobaldi), enviaram representantes com seus próprios navios, ou em colaboração com mercadores portugueses. Enquanto alguns desses italianos se limitaram a desenvolver uma atividade meramente comercial, outros participaram ativamente das tentativas de conquista das mais importantes praças orientais, chegando, não poucas vezes, a ocupar lugares de preeminência na estrutura administrativa e militar do nascente Estado da Índia. ${ }^{34}$

\footnotetext{
32 Cf. RADULET, Carmen. Os italianos em Portugal. In: Chandeigne, Michel (Org.). Lisboa Ultramarina, 14151580: a invenção do mundo pelos navegadores portugueses. Rio de Janeiro: Jorge Zahar, 1992. p. 96-97.

33 Id. Ibid. Os descobrimentos portugueses e a Itália: ensaios filológico-literários e historiográficos. Trad. de Edite Caetano. Intro. de Luis de Albuquerque. Lisboa: Vega, 1991. p. 61.

34 Cf. RADULET, Carmen. Os italianos em Portugal. In: Chandeigne, Michel (Org.). Lisboa Ultramarina, 1415-1580: a invenção do mundo pelos navegadores portugueses. Rio de Janeiro: Jorge Zahar, 1992. p. 100.
} 
Com a intensificação e consolidação das expedições marítimas, no final do século XV e meados do XVI, aumentou o número de estrangeiros ${ }^{35}$ em Portugal, entre os quais numerosos italianos, que o escolhiam como base para as suas atividades. De fato, no início do século XVI, a colônia italiana em Portugal se reforçou numericamente e aumentou consideravelmente o seu peso econômico e político; ${ }^{36}$ a ponto de alguns dos italianos terem se tornado muito importantes e obtido da Coroa portuguesa posições de privilégio que várias vezes os colocaram em situação de concorrência com a burguesia local..$^{37}$

Os italianos puseram a serviço de Portugal as suas idéias e aptidões, especialmente no campo da cartografia e de certas técnicas de navegação. Até certo ponto, trouxeram também os ensinamentos da Renascença e do Humanismo, ${ }^{38}$ particularmente por meio da divulgação de textos clássicos então redescobertos, como a Geografia de Ptolomeu. $^{39}$

Contudo, uma das maiores contribuições dos italianos para Portugal foi, sem dúvida, na área financeira, ${ }^{40}$ sem a qual os portugueses não teriam alcançado tanto sucesso nas explorações ultramarinas. ${ }^{41}$ De fato, a atividade comercial e financeira em Portugal de poderosas famílias italianas permitiu o estabelecimento de intensas relações com a Coroa

35 Sobre a participação financeira alemã em Portugal nos séculos XV e XVI, vide: KELLENBENZ, Hermann. Os mercadores alemães de Lisboa por volta de 1530. Revista Portuguesa de História, t. IX, p. 125-140, 1960; e ALMEIDA, A. A. Marques de Mercadores Cristãos-novos no negócio da especiaria (entre 1480 e 1530). Disponível em: <http://www.fl.ul.pt/unidades/sefarditas/textos/textos_6.htm>. Acesso em: 10 dez. 2008.

36 Cf. RADULET, Carmen. Relações de Portugal com a Itália. In: Albuquerque, Luís de. Dicionário de história dos descobrimentos portugueses. Lisboa: Caminho, 1994. v. 1. p. 535.

37 Como, e.g., Bartolomeu Marchioni (ou Marchione), banqueiro e mercador florentino, que atuou na virada do século XV para o XVI, estabeleceu-se em Lisboa e foi amigo de D. João II e de D. Manuel I. Foi um dos maiores banqueiros italianos e financiou várias expedições dos descobrimentos, a partir de 1474. Colaborando com os Medici e com outros banqueiros florentinos, assegurou a D. João II a cobertura financeira de várias expedições ultramarinas, entre as quais a viagem de Pêro da Covilhã e de Afonso de Paiva. Mais tarde, o mesmo mercador participou com investimentos e com navios próprios na exploração do caminho marítimo para a Índia, sendo um dos primeiros mercadores estrangeiros a participar na comercialização das especiarias, logo na expedição de Pedro Álvares Cabral, entre 1500 e 1501. Em 1505, na armada de D. Francisco de Almeida, formou um consórcio com outros italianos e alemães (Antônio Welser, os Fugger e outras firmas alemãs, tendo o grupo dos alemães participado com 20 mil cruzados, e o grupo de Marchioni com 29.400). (Cf. RADULET, Carmen. Relações de Portugal com a Itália. In: Albuquerque, Luís de. Dicionário de história dos descobrimentos portugueses. Lisboa: Caminho, 1994. v. 1. p. 536; AZEVEDO, J. Lúcio de. Épocas de Portugal económico: esboços de história. Lisboa: Clássica Editora, 1929, p. 97; e SARAIVA, José Hermano. História de Portugal. Dicionário de Personalidades. Lisboa: QuidNovi, 2004. Disponível em $<$ http://carreiraindia.net/2007/12/protagonistas/bartolomeu-marchionni>. Acesso em: 10 dez. 2008).

38 Sobre o Humanismo jurídico em Portugal, v. COSTA, Mário Júlio de Almeida. História do direito português. 3. ed. 5. reimpr. Coimbra: Almedina, 2003. p. 319, item 55.

39 Cf. ARNOLD, David. A Época dos descobrimentos: 1400-1600. Tradução rev. e prefaciada por Luís Felipe Barret. Lisboa: Gradiva, 1983. p. 29-30.

40 Cf. MAURO, Frédéric. Portugal, o Mediterrâneo e o Atlântico em 1493 e 1993. Tradução por Carlos A. A. Ferraz e Araújo. Politéia: História e Sociedade, Vitória da Conquista, v. 2, n. 1, p. 13-20, 2002. cit. p. 17-18.

41 Cf. PESTANA, Fabio Ramos. No Tempo das Especiarias. São Paulo: Contexto, 2007. p. 41. 
portuguesa, desde a época de D. Afonso V ${ }^{42} \mathrm{Na}$ virada do século XV e em meados do XVI, Lisboa já era um efervescente centro urbano, ${ }^{43}$ um dos grandes entrepostos comerciais da Europa, cujos mercados abastecia com os produtos orientais. Era o primeiro porto do Mundo, com uma população cosmopolita. Mercadores de toda a Europa tinham sede ou entrepostos comerciais na cidade, ${ }^{44}$ mas os italianos dominavam o cenário econômico e eram os principais parceiros da Coroa portuguesa nos empreendimentos comerciais. ${ }^{45} \mathrm{~A}$ esse respeito, vale conferir o que afirma o historiador Fabio Ramos Pestana:

As aplicações dos judeus foram fundamentais para a constituição da armada dos navios responsáveis pelo descobrimento do caminho para a Índia, e, mais tarde, para o fortalecimento da rota do Brasil, sobretudo quando as frotas foram ameaçadas pelo bloqueio naval holandês. Entretanto, não foram o bastante para saciar a cobiça dos portugueses. Depois de aberta a rota para o Oriente, após o período em que os aportes financeiros da comunidade judaica haviam bancado satisfatoriamente a exploração da costa africana, Vasco da Gama retornou a Portugal, em 1499, trazendo consigo a pimenta e outras especiarias, proporcionando lucro excepcional aos investidores, fato que atrairia ainda mais a atenção de mercadores e banqueiros italianos. $\mathrm{O}$ envolvimento dos italianos com os portugueses não era recente; desde o século $\mathrm{XV}$, no princípio da expansão ultramarina, alguns mercadores italianos já contribuíam para a armada dos navios lusitanos em troca de participação nos lucros obtidos. E, inclusive, entre a tripulação, encontravamse cosmógrafos e tripulantes italianos ocupando cargos de comando. ${ }^{46}$

42 Cf. MORENO, Humberto Baquero. Portugal: do Mediterrâneo ao Atlântico, no século XV. Revista da Faculdade de Letras: História. Porto, série II, vol. 13, 1996, pp. 187-203. cit. p. 201.

43 Os negócios eram concentrados na Rua Nova dos Mercadores, a mais importante da cidade, composta de grandiosos edifícios de ambos os lados. Lisboa, subitamente rica e abastada, colorida pelo exotismo dos seus adornos e das suas gentes, era então o espanto de quantos a visitavam com curiosidade e interesse. Conforme afirma Damião De Góis, "Nunca vi fazer semelhante coisa em nenhuma outra cidade da Europa. Por aqui se pode facilmente avaliar a grandeza de Lisboa e o número dos seus habitantes". (Apud NICOLA, Liliana. ABC da Expansão Portuguesa. Disponível em: <http://www2.crb.ucp.pt/Historia/abced\%C3\%A1rio/lisboa/lisboa.htm>. Acesso em: 10 dez. 2008).

44 Cf. CORRÊA, Francisco António. História económica de Portugal. Lisboa: Tip. da Emprêsa nacional de publicidade, 1929-30. v. 1, p. 148.

45 Cf. PESTANA, Fabio Ramos. Por mares nunca dantes navegados: a aventura dos descobrimentos. São Paulo: Contexto, 2008. p. 35; e GUIRADO, Maria Cecília. Possível gênese da globalização: notícias de aquém e de além-mar. Comunicação: Veredas, Marília, a. 2, n. 2, p. 271-283, nov. 2003. cit. p. 276.

46 Cf. PESTANA, Fabio Ramos. Por mares nunca dantes navegados: a aventura dos descobrimentos. São Paulo: Contexto, 2008. p. 35. 
O apogeu da expansão marítima portuguesa ocorreu durante o reinado de D. Manuel $\mathrm{I}^{47}$ e a influência italiana cresceu na mesma proporção. Com efeito, nos primeiros anos do século XVI o poder econômico dos banqueiros e mercadores florentinos e a posição de privilégio de que gozavam na Corte de D. Manuel I eram de tal peso que lhes permitiu a estipulação de contratos particulares com a Coroa. ${ }^{48} \mathrm{O}$ êxito e os enormes lucros obtidos graças ao comércio dos produtos orientais induziram os italianos que operavam em Portugal a intensificarem ainda mais sua atividade e a aumentarem os investimentos. Nesse sentido, merece destaque a participação de grandes casas comerciais, como a dos Marchioni, Bardi (ou Barde) e Sernigi, que chegam até a idealizar um acordo com D. Manuel I para estabelecer em Porto Pisano (atual Livorno) um ponto de distribuição das especiarias no Mediterrâneo e na Europa Central, ${ }^{49}$ em concorrência com Veneza. ${ }^{50}$

O grosso do capital investido por banqueiros italianos vinha de empréstimos diretos à Coroa portuguesa e a particulares interessados em armar novos navios. A Coroa utilizava-se dos lucros gerados pelo comércio das especiarias e da prata para quitar as dívidas, sendo feito o pagamento muitas vezes em natura e, apesar dos custos fixos elevados e a perda de grande número de embarcações, o lucro obtido ainda assim era altíssimo. Em decorrência desse círculo vicioso, as divisas geradas pela expansão ultramarina se esvaíram com o pagamento de dívidas contraídas para a manutenção da empreitada, aliada aos custos elevados do sustento de uma Corte luxuosa ${ }^{51}$ e da nobreza parasitária, ao mesmo tempo em que os estamentos mais baixos continuavam na miséria. ${ }^{52}$

Uma estada prolongada em Portugal induziu inúmeros italianos a se integrarem definitivamente ao país que os acolheu. Em alguns casos, os representantes das grandes casas comerciais e alguns dos seus colaboradores, muitas vezes pertencentes à nobreza mercantil e bancária, contraíram casamento com pessoas da nobreza portuguesa (é o caso, por exemplo, dos Pessanha, dos Perestrelo, dos Bardi). Noutros casos, os italianos requereram a naturalização à Coroa portuguesa: a esse respeito, é emblemático o caso de Girolamo Sernigi, que em 1511 obtém de D. Manuel I o título e os privilégios de cidadão

47 Cf. BELLINI, Lígia. Notas sobre cultura, política e sociedade no mundo português do século XVI. Tempo, Rio de Janeiro, v. 4, n. 7, p. 143-167, 1999. cit. p. 148.

48 Cf. RADULET, Carmen. Os descobrimentos portugueses e a Itália: ensaios filológico-literários e historiográficos. Trad. de Edite Caetano. Intro. de Luis de Albuquerque. Lisboa: Vega, 1991. p. 65.

49 Id. Ibid. Relações de Portugal com a Itália. In: ALBUQUERQUE, Luís de. Dicionário de história dos descobrimentos portugueses. Lisboa: Caminho, 1994, v. 1,. p. 536.

${ }^{50}$ Id. Os italianos em Portugal. In: CHANDEIGNE, Michel (Org.). Lisboa ultramarina, 1415-1580: a invenção do mundo pelos navegadores portugueses. Rio de Janeiro: Jorge Zahar, 1992. p. 101.

51 Cf. BELLINI, Lígia. Notas sobre cultura, política e sociedade no mundo português do século XVI. Tempo, Rio de Janeiro, v. 4, n. 7, p. 143-167, 1999. cit. p. 149.

52 Cf. PESTANA, Fabio Ramos. No tempo das especiarias. São Paulo: Contexto, 2007. p. 42. 
de Lisboa, e em 1515 o mesmo rei reconhece o seu brasão e o registra no Armorial Geral, como fidalgo e nobre de cota d'armas. ${ }^{53}$

A colaboração italiana não se limitou, todavia, aos campos econômico, comercial e político, mas igualmente condicionou profundamente o desenvolvimento cultural, artístico e científico de Portugal. Com efeito, em Portugal uma parcela importante das novas idéias sobre arte e diversos ramos do saber filosófico e literário era originária da Itália, ${ }^{54}$ porquanto alguns italianos que, se transferiram para Lisboa ou Coimbra, trouxeram para Portugal os novos fermentos culturais típicos da Itália daquela época. ${ }^{55}$ Por toda a Europa as cidades italianas eram consideradas paradigmas de centros "modernos", nos quais o saber e as artes desenvolviam-se pari passu com a prosperidade econômica. Isto era reforçado pelos contatos de intelectuais italianos com os reis portugueses. ${ }^{56}$

É este o caso, para citar apenas alguns nomes de italianos que atuaram em Portugal durante a virada do século XV e em meados do XVI, de pintores e arquitetos, como Antonio Florentin, Antonio, Pietro e Ferdinando Tacca, Filippo Terzi; matemáticos e cosmógrafos, como Francisco Albano; latinistas, como Mateo de Pisa, frei Giusto Baldini, Cataldo Aquila Siculo; escritores, como Scotto Ascanio; editores e tipógrafos, como Gian Pietro Buonomini. Assim, estes homens de cultura, ao lado dos Pessanha, Marchioni, Perestrelo, Sernigi, Nardi, etc, deram uma contribuição muito importante para o desenvolvimento da vida econômica, cultural e científica de Portugal, influindo profundamente também sobre a evolução da história política e artística do império oriental. ${ }^{57}$ Até mesmo no campo da contabilidade portuguesa daquela época houve a influência das cidades-estado italianas. ${ }^{58}$

5. Rápida conclusão: apenas uma hipótese que não deve ser descartada

Conquanto este trabalho tenha sido fruto de uma pesquisa muito limitada (tanto no tempo, como no espaço), de tudo que até aqui se expôs, fica muito evidente a

53 Cf. RADULET, Carmen. Os italianos em Portugal. In: CHANDEIGNE, Michel (org.). Lisboa Ultramarina, 1415-1580: a invenção do mundo pelos navegadores portugueses. Rio de Janeiro: Jorge Zahar, 1992. p. 102.

54 Cf. BELLINI, Lígia. Notas sobre cultura, política e sociedade no mundo português do século XVI. Tempo, Rio de Janeiro, v. 4, n. 7, p. 143-167, 1999. cit. p. 144.

55 Cf. RADULET, Carmen. loc. cit.

56 Cf. BELLINI, Lígia. op. cit. p. 151

57 Cf. BELLINI, Lígia. Notas sobre cultura, política e sociedade no mundo português do século XVI. Tempo, Rio de Janeiro, v. 4, n. 7, p. 143-167, 1999. cit. p. 151.

58 Cf. LIRA, Miguel Maria Carvalho. Evolução do pensamento contabilístico português até ao século XIX: aspectos históricos da influência italiana na introdução do método digráfico. 2004. Tese (Mestrado) contabilidade e auditoria - UAb, Coimbra. Disponível em: <http://www.univ-ab.pt/sda/mca/lira.html >. Acesso em: 10 dez. 2008. 
enorme influência italiana em Portugal nos séculos XV e XVI e as transformações que essa interação produziu em toda a sociedade lusitana daquela época.

Se não parece intuitivo que tamanha influência em diversas áreas e aspectos da sociedade portuguesa também possa ter repercutido no campo do Direito, inspirando os juristas manuelinos quando da criação da "ação decendiária" ou "de assinação de dez dias"; ou que o poder político e a grande influência financeira de alguns italianos junto a D. Manuel I e à sua Corte tenham, de alguma forma, servido de mola propulsora ou exercido pressão para a introdução em Portugal de um procedimento judicial mais célere que atendesse melhor aos interesses dos credores, a exemplo do "mandatum de solvendo cum clausula iustificativa", com o qual os italianos já estavam culturalmente habituados; é uma hipótese que não pode ser descartada.

De fato, a contribuição do direito estatutário italiano para a introdução em Portugal de um procedimento do tipo monitório deve ser considerada, ao menos para libertar a análise do instituto de uma concepção exclusivamente lusófila e, por isso mesmo, limitada da História - como quase tudo que se viu escrito sobre a "ação decendiária" até o momento.

Brasília, dezembro de 2008.

\section{Referências}

ALMEIDA, A. A. Marques de. Mercadores cristãos-novos no negócio da especiaria (entre 1480 e 1530). Disponível em: $<$ http://www.fl.ul.pt/unidades/sefarditas/textos/textos_6.htm>. Acesso em: 4 dez. 2008.

ARNOLD, David. A época dos descobrimentos: 1400-1600. Tradução rev. e prefaciada por Luís Felipe Barreto. Lisboa: Gradiva, 1983.

AZEVEDO, J. Lúcio de. Épocas de Portugal económico: esboços de história. Lisboa: Clássica Editora, 1929.

AZEVEDO, Luiz Carlos de. Introdução à história do direito. 2. ed., rev. e ampl. São Paulo: Revista dos Tribunais. 2007.

. O Reinado de D. Manuel e as Ordenações Manuelinas. Revista da Faculdade de Direito da Universidade São Paulo, São Paulo, v. 95, p. 19-32, jan./dez. 2000.

BELLINI, Lígia. Notas sobre cultura, política e sociedade no mundo português do século XVI. Tempo, Rio de Janeiro, v. 4, n. 7, p. 143-167, 1999.

CALASSO, Francesco. Medio evo del diritto. Milano: Giuffrè, 1954. v. 1.

CHIOVENDA, Giuseppe. Istituzioni di diritto processuale civile. Napoli: Jovene, 1950. v. 1. 
CORRÊA, Francisco António. História económica de Portugal. Lisboa: Tip. da Emprêsa nacional de publicidade, 1929-30. v. 1.

COSTA, Mário Júlio de Almeida. História do direito português. 3. ed. 5. reimpr. Coimbra: Almedina, 2003.

GUIRADO, Maria Cecília. Possível gênese da globalização: notícias de aquém e de além-mar. Comunicação: Veredas, Marília, a. 2, n. 2, p. 271-283, nov. 2003.

KELLENBENZ, Hermann. Os mercadores alemães de Lisboa por volta de 1530. Revista Portuguesa de História, t. IX, p. 125-140, 1960.

LIRA, Miguel Maria Carvalho. Evolução do pensamento contabilístico português até ao século $X I X$ : aspectos históricos da influência italiana na introdução do método digráfico. Coimbra, 2004. Tese de mestrado em contabilidade e auditoria - UAb. Disponível em: $<$ http://www.univ-ab.pt/sda/ mca/lira.html>. Acesso em: 4 dez. 2008.

LOBÃO, Manuel de Almeida e Sousa. Tratado pratico compendiario de todas as acções summarias. Lisboa: Imprensa Nacional, 1867.

MAURO, Frédéric. Portugal, o Mediterrâneo e o Atlântico em 1493 e 1993. Tradução por Carlos A. A. Ferraz e Araújo. Politéia: História e Sociedade, Vitória da Conquista, v. 2, n. 1, p. 13-20, 2002.

MORAES, José Rubens de. Evolução histórica da execução civil no direito lusitano. 2005. Dissertação (Mestrado) - Faculdade de Direito, Universidade de São Paulo, São Paulo.

MORENO, Humberto Baquero. Portugal: do Mediterrâneo ao Atlântico, no século XV. Revista da Faculdade de Letras: História. Porto, série II, v. 13, p. 187-203, 1996.

NICOLA, Liliana. ABC da expansão portuguesa. Disponível em: $<$ http://www2.crb.ucp.pt/Historia/ abced\%C3\%A1rio/lisboa/lisboa.htm>. Acesso em: 4 dez. 2008.

OLIVEIRA, Antônio de Almeida. A assignação de dez dias no foro commercial e civil. Nova ed. corr. Lisboa: A. M. Teixeira, 1915.

Ordenaçoens do Senhor Rey D. Manuel. Livro III. Coimbra: Real Imprensa da Universidade. 1797. PESTANA, Fabio Ramos. No tempo das especiarias. São Paulo: Contexto, 2007.

Por mares nunca dantes navegados: a aventura dos descobrimentos. São Paulo: Contexto, 2008.

RADULET, Carmen. Os descobrimentos portugueses e a Itália: ensaios filológico-literários e historiográficos. Trad. de Edite Caetano. Intro. de Luis de Albuquerque. Lisboa: Vega, 1991.

Os italianos em Portugal. In: CHANDEIGNE, Michel (Org.). Lisboa Ultramarina, 1415 1580: a invenção do mundo pelos navegadores portugueses. Rio de Janeiro: Jorge Zahar, 1992.

. Relações de Portugal com a Itália. In: ALBUQUERQUE, Luís de. (Dir.). Dicionário de história dos descobrimentos portugueses. Lisboa: Caminho, 1994. v. 1. 
SARAIVA, José Hermano. História de Portugal: Dicionário de Personalidades. Lisboa: QuidNovi, 2004. Disponível em: <http://carreiradaindia.net/2007/12/protagonistas/bartolomeu-marchionni/>. Acesso em: 4 dez. 2008.

SELLA, Pietro. Il procedimento civile nella legislazione statutaria italiana. Milano: Hoepli, 1927.

SICILIANI, Tommaso. Procedimento per ingiunzione. In: Nuovo digesto italiano. Torino: UTET, 1938. v. 16.

SOUZA, Joaquim José Caetano Pereira e. Primeiras linhas sobre o processo civil. Accommodadas ao Foro do Brasil ate o anno de 1877 por Augusto Teixeira de Freitas. Rio de Janeiro: H. Garnier, 1907.

TALAMINI, Eduardo. Tutela monitória: a ação monitória - Lei 9.079/95: doutrina, jurisprudência anotada, aproximadamente 200 acórdãos. 2. ed. rev., atual. e ampl. São Paulo: Revista dos Tribunais, 2001.

TUCCI, José Rogério Cruz e. Ação monitória: Lei 9.079, de 14.7.1995. 3. ed. rev. atual. e ampl. São Paulo: Revista dos Tribunais, 2001. 